\title{
Planets and Time: A Timaean Puzzle
}

\author{
Karel Thein
}

\begin{abstract}
In the Timaeus, the issue of planets is revelatory of the twofold subject of the plausible account of how our universe acquired its present shape. If Timaeus speaks about the nature of the Whole and about human nature, the creation of the planets is where these two parts of his account meet and intersect. To clarify this suggestion, the chapter starts with the creation of time and with its role in Timaeus' account (some more metaphysical remarks on the nature of time are relegated to the Postscript). The second part of the chapter turns to the planets as a pivotal moment where Timaeus passes from the immortal to the mortal species. This passage will play an important role in explaining why Timaeus uses various temporal idioms without offering a unified theory of time.
\end{abstract}

\section{Keywords}

Plato - Timaeus - planets - time

In the overall framework of Timaeus' plausible account of how our universe acquired its present shape, the issue of planets is revelatory of the twofold nature of Timaeus' task: Timaeus is invited to speak about the nature of the Whole and about human nature. The planets, I will suggest, are precisely where these two parts of the story meet and intersect.

Before focusing on this intersection, in other words on planets and human beings, I need to start with Timaeus' rather entangled narrative of how-and especially why - the planets were created in the first place. By the same token, this first part of my contribution cannot avoid the issue that is at the heart of this narrative, namely the creation of time. I will limit myself to the role of the planets and time within Timaeus' cosmic story and leave aside a more metaphysical inquiry into time, which goes necessarily beyond the text of our dialogue. A taste of such an inquiry is given in the "Postscript," which offers some further remarks on how Timaeus speaks about time and what are some possible implications of his story for a more abstract treatment of it. In the second part of my contribution, I will turn to the planets as a pivotal moment where Timaeus' story passes from the immortal to the mortal living species. 
The first part of my contribution starts naturally with line $37 \mathrm{c} 6$, where we meet the Demiurge who pauses to take a look at his creation so far. This is actually the only time in the story that we observe him doing so, and this unusual dramatic device has a reason: while contemplating the world consisting of a soul and a body put together, the Demiurge conceives an idea, which he will realize in the guise of planets, including the structure of their motions that we call "time." In order to properly evaluate this invention, we first need to assume the posture of the demiurge so as to see what exactly it is that he contemplates at this point of the story.

On the flatly descriptive level, we can observe the world's body and its soul woven intricately together in a way which implies that the soul is itself a tridimensional structure that both encompasses and permeates the world as a physical compound. Obviously, the soul is not visible as such, and the verb Timaeus employs, noein, signals that we grasp much more than the observable facts. What we understand is not only that the universe moves, but that its motion is internally animated. To which the Demiurge reacts as follows:

Now when the father who had begotten the universe observed it set in

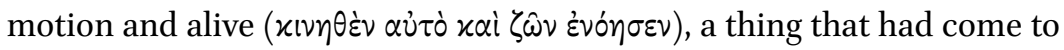

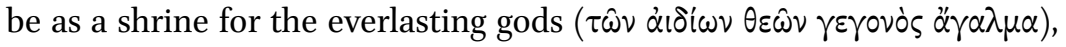
he was well pleased, and in his delight he thought of making it more like

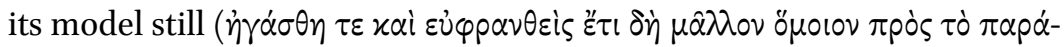

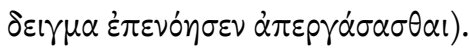

$37 \mathrm{c} 6-\mathrm{d} \mathbf{1}^{1}$

Two things happen here: first, we have the thoughtful contemplation whose joyful character is emphasized by the verbs agazō and euphrainō, but also by the description of the object in question as tōn aidiōn theōn agalma, a kind of charming sanctuary, a wonderful invitation for gods to be at home in the universe-here we may notice a certain temporal oscillation of the narrative which conflates what already is and what is yet to come. ${ }^{2}$ For now, we are more interested in the second moment: the state of joyful contemplation (verb noein) which mixes intellectual alertness with the father's affection for his offspring. This state inspires a new idea, which will carry the project still further forward (verb epinoein). In other words, looking at what is already wonderful,

1 Here as elsewhere the translation I use is Zeyl, Plato: Timaeus.

2 On agalma as joy-provoking image see Kerényi, "Agalma, eikon, eidolon." Cf. Cohen, "Etymology of Greek agalma, agallô, agallomai." Agallomai means to exult, to rejoice greatly; it designates the rapture of those who find themselves face to face with the divine. 
the Demiurge thinks about how to make it even more so. First, I will quote this train of Demiurgic thought in Zeyl's translation which reflects probably the most common interpretation of the text:

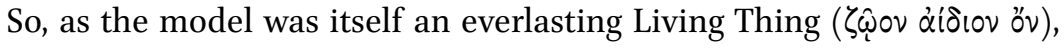
he set himself to bringing this universe to completion in such a way that it, too, would have that character to the extent that was possible. Now it was the Living Thing's nature to be eternal ( $\alpha i \omega$ vios), but it isn't possible to attach [the eternal nature] fully to anything that is begotten. And so

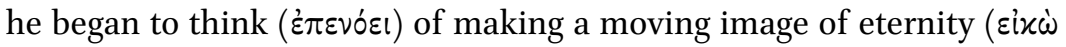

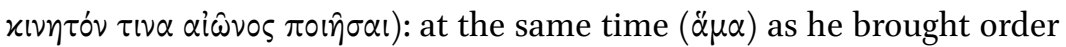

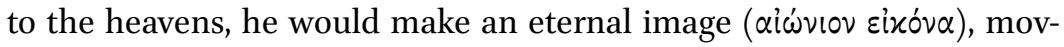

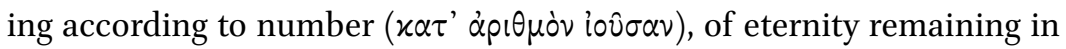

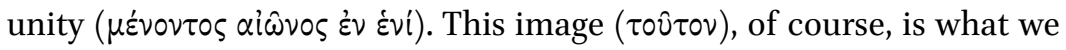
now call "time."

$37 \mathrm{~d} 1-7$

At first sight, this reasoning is more than a little bit strange: if it is eternity and unity as such that are to be passed on, insofar as possible, to the universe, then the introduction of time is not only of little help, but it would actually seem to make the difference even bigger since it would enable us to count, thanks to the distinctly observable motions, an increasing number of different states. This probably means that the effect intended by the Demiurge is not one of an undifferentiated eternality, but consists rather in conferring to the world a still higher degree of nobility which is not entirely unlike the value of what is aionios or aidios - in other words, the value proper to living beings alone. Here it should be noted these two expressions (of which the first, aionios, may well be Plato's coinage) seem to be interchangeable; or, at least, the text of the dialogue offers no clue as to their possible difference. To which a caveat must be added: the quoted passage contains a number of lexical problems and rather peculiar constructions, and things will not get better in the next lines. I will leave aside most of the textual issues, including the disconcerting presence of various tenses, ${ }^{3}$ and focus only on what is crucial for our understanding of what exactly it is that we "now call time." And because this understanding can only be gained if we clarify the function of time, we can start by emphasizing

3 On the textual problems in this part of the Timaeus see Brague, "Pour en finir avec 'le temps, image mobile de l'éternité' (Platon, Timée, 37d)." 
the double use of aidios, which applies not only to what simply is eternal, but also to what came to be but will not perish. ${ }^{4}$

Hence the peculiar expression "eternal image" (aiōnion eikōn) and the much-discussed question of what exactly this image is and how it differs from what it is an image of. As for the first part of this question, Zeyl's translation offers an apparently clear answer: the image in question is time, which implies that the masculine accusative touton in the last quoted sentence refers to the feminine noun eikōn in the previous sentence. ${ }^{5}$ The philosophical sense we obtain from this reading follows in the steps of Philo of Alexandria who was the first, as far as we know, to take the text to speak about time as the "the imitation of eternity" (mimēma aiōnos). ${ }^{6}$ However, there are two other candidates for the meaning of touton at $37 \mathrm{~d} 7$, and they are both masculine nouns. The first of them is the accusative ouranon at $37 \mathrm{e} 6$, which seems syntactically rather disconnected from touton, and would yield a more direct identification of time with the motion of the whole universe than both the whole sentence and its wider context suggest. The second is the accusative arithmon, which seems quite naturally placed to be referred back by the touton in the next clause. ${ }^{7}$ I find the choice of arithmos as the referent of touton very appealing, and not only for syntactical reasons. I believe that it does not at all contradict the

4 It is beyond the scope of my contribution to address the debates about Plato and the introduction of "eternity" into philosophical discourse. My own view concerning the Timaeus is that, simply put, this dialogue deals less with the metaphysics of eternity versus time than with the premise of an everlasting divine life whose perfection is neither augmented nor diminished by duration - such a life still echoes in Boethius' definition of eternity as divine life, which is also an exegesis of the Timaeus: "it is one thing to progress like the world in Plato's theory through everlasting life, and another thing to have embraced the whole of everlasting life in one simultaneous present" (Consolation, V vi.9-11; translated by V. E. Watts, London, Penguin, 1969). So even if eternity has no externally measurable duration, there is still some sort of duration in eternity insofar as what is eternal is alive, hence somehow active (here I agree with Stump and Kretzmann, "Eternity," and Leftow, Time and Eternity). In any case, the positing of two very different kinds of unceasing life is necessarily distinct from the discussions which concern the (atemporal) status of Platonic Forms. On these discussions, including a perceptive criticism of some earlier interpretations, see Mason, "Why Does Plato Believe in a Timeless Eternity?"

5 This is grammatically sound. For different options of how to construe the whole quite entangled sentence see Brague, "Pour en finir", 66, and Johns, "On the translation of Timaeus 38b6-c3."

6 Philon, Quis rerum divinarum heres sit (34) 165 (= III 38.15 Cohn-Wendland).

7 Some modern translations seem to reproduce the ambivalence of the original. See e.g. Cornford's rendering: "But he took thought to make, as it were, a moving likeness of eternity; and, at the same time that he ordered the Heaven, he made, of eternity that abides in unity, an everlasting likeness moving according to number - that to which we have given the name Time." What does "that" refer to? To "likeness" or to "number"? 
traditional reading, which makes time into the image of eternity; but it enables us to refine this reading and to give it much more flesh by bringing into focus the particular cosmic structures which serve to introduce time into the divinely produced universe.

The first statement in favor of my attempt is simply the explicit characterization of time offered already at $37 \mathrm{~d} 5^{-6}$ : chronos is a number, arithmos, "according to which" the eternal, yet produced, image (whatever it is) moves (cf. kat' arithmon iousan). This is the second favorable statement: it would seem that, here as elsewhere in Plato, to be a produced image (with the exception of speech as image) means being something which is visibly and materially part of the sensible world - but neither time nor number, if considered on the purely abstract level, are of such a nature. What they require to fit the present context of making things is a support which can actually move, "according to number," in the three-dimensional world. And it is the creation of such a support, or the completion of such a creation, that Timaeus will go on to describe in the guise of the making of planets. As Timaeus will state later on, "time really is [or, as Archer-Hind has it, "arises from"] the wanderings of these bodies." (39d1-2)

The planets, therefore, are what connects lines $37 \mathrm{~d}_{1}-7$ with what follows in the next four to five Stephanus pages. My aim is therefore to demonstrate that these pages only confirm that time as such, taken abstractly, is not the image in question, although time, defined as number, is embedded in what the image in question - namely the celestial bodies - does or, more exactly, in how that image moves. Here I assume that, throughout the Timaeus, the motion described by the verb kinein implies physicality: only bodies are properly kinoumena. ${ }^{8}$ And if so, then the best candidate for the role of the moving yet eternal image are the planets together with the structure of their various motions including the relation between this structure and the sphere of the fixed stars. Time as number-a mathematical structure-is not identical to this image, but it enables the planets themselves, as living beings whose motions express the appropriate number, to maintain the ordered regularity of their motion. This, as we will see further on, is an important aspect of the created image: not only it is visible, and therefore corporeal, but this "eternal image," once created, can be self-governing only in virtue of its being alive. This dimension of the argument should not be forgotten: there is little doubt that aiōnios, like aiōn, strongly implies an everlasting life and could hardly be predicated of either something only abstract or something entirely inanimate. Taking into account

8 Correlatively, I doubt that the souls as described by Timaeus, including the world soul and the souls of the stars, are simply "incorporeal" (while having spatial properties) without further qualifications. For more on this issue see Thein, "Soul and incorporeality in Plato." 
this last feature of the argument (which, in contrast to its commentators, is far from distinguishing between various modalities of everlastingness, but has its eye on the everlasting glory of what is either simply divine or divinely fabricated), I propose a modified translation of $37 \mathrm{~d} 1-7$ with a freer rendering of aiōnios and aiōn, and a differently construed last sentence:

So, as the model was itself an eternal Living Thing, he set himself to bringing this universe to completion in such a way that it, too, would have that character to the extent that was possible. Now it was the Living Thing's nature to be eternally alive, but it isn't possible to attach [the eternal life] fully to what is begotten. And so it occurred to him to make a moving image of the eternal life; at the same time as he brought order to the universe, he would make an eternally living image of the eternal life that remains in unity: [the image] moving according to that number (touton) which we call "time."

Once Timaeus turns to the planets as such, the proposed reading will receive further and quite explicit support. First, however, we are offered a supplementary explanation concerning the issue of time and tenses $\left(37 \mathrm{~d}_{1}-38 \mathrm{~b} 5\right)$. Right from the first sentence of this supplement, the presence of planets is presupposed insofar as the talk about days and nights, months and years would make little sense without them:

For before the heavens came to be ( $\pi$ piv oujpavòv $\gamma \varepsilon v \varepsilon \dot{\sigma} \sigma \alpha \mathrm{l}$ ), there were no days or nights, no months or years. But now, at the same time $(\ddot{\alpha} \mu \alpha)$ as he framed the heavens, he devised their coming to be.

$37 \mathrm{e} 1-3$

Here "heavens" refer to the state of the universe at the moment of the planets' making which is as yet to be accounted for: when Timaeus will be done with the more formal issues, the planets will enable the Demiurge to project a new kind of time literally into the world. In the two quoted sentences we also notice that Timaeus gets around the dilemma of "how could there have been some 'before and after' if there was still no time." He does not

9 My version of the last sentence concurs with Wilberding, "Eternity in Ancient Philosophy": "But he took thought to make a kind of moving image of eternity ( $\left.\alpha i \omega^{\prime} v\right)$, and simultaneous

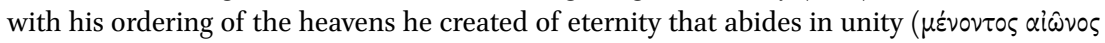
$\left.\dot{\varepsilon} \nu \varepsilon^{\prime} i^{\prime}\right)$ an eternal ( $\left.\alpha i \omega^{\prime} v \iota_{0}\right)$ image moving according to number, and this number is what we have labeled "time." 
repeat that the planets, as the next stage of creation, will only be produced after the world soul and the world's basic body, but prefers to point out that there were no days, no nights, no months, and no years $\pi$ piv ovjpavòv $\gamma \varepsilon v \varepsilon \dot{-}-$ $\sigma \theta \alpha$, which is a general expression specified, in the next sentence, by $\alpha \mu \alpha$ which can mean "at the same time," but also "together with." Both meanings take off the edge of sequentiality, and so does the parallel expression used by

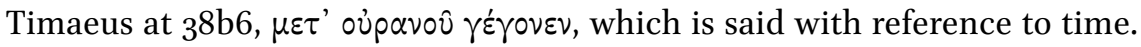
Here Timaeus seems to imply a certain simultaneity of the heavens and time despite the fact that his description of how the Demiurge produces the heavens in its present shape proceeds in three neatly distinct steps, where three very different procedures are employed: first, the world's body is inscribed within the structure of the world soul; then, the planets are added; finally, the fixed stars are fashioned as the likeness of the first of the species that compose the intelligible model of the universe. Sequential or not, these are fundamentally different operations.

The cosmic structure which results from all these operations (of which the second and the third one are still to be described in some detail) forms an implicit background for the next part of the explanation where Timaeus introduces two basic dimensions of time, one which is generically akin to time as number and hence structure, and another one which follows from the changes of particular bodies "within" this structure, including the processes of generation and corruption. This explanation is clearly an aside to the main storyline; it is designed so as to highlight the inescapable duality implied in our conception of time and, by consequence, in our ways of speaking about it:

These [sc. days, nights, months, and years] all are parts of time ( $\mu \varepsilon \dot{p} \eta$ Xpóvov), and was and will be are forms of time that have come to be (xpóvou $\gamma \varepsilon \gamma \circ v o ́ \tau \alpha$ $\left.\varepsilon^{\prime} \delta \eta\right)$. Such notions we unthinkingly but incorrectly apply

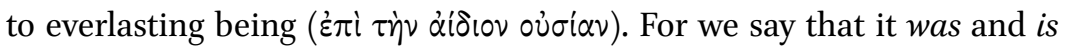
and will be, but according to the true account only is is appropriately said of it. Was and will be are properly said about the becoming that passes in time, for these two are motions. But that which is always changeless and motionless cannot become either older or younger in the course of time ( $\delta$ ¿ Xpóvou) - it neither ever became so, nor is it now such that it has become so, nor will it ever be so in the future. And all in all, none of the characteristics that becoming has bestowed upon the things that are borne about in the realm of perception are appropriate to it. These, rather, are forms of time that have come to be-time that imitates eter-

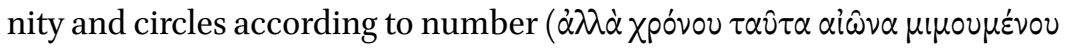




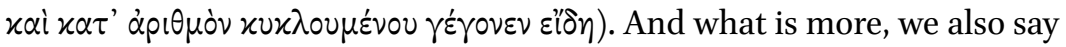
things like these : that what has come to be is what has come to be, that what is coming to be is what is coming to be, and also that what will come to be is what will come to be, and that what is not is what is not. None of these expressions of ours is accurate. But I don't suppose this is a good time right now to be too meticulous about these matters.

$37 \mathrm{e} 3-38 \mathrm{~b} 5$

The initial division is clear: there are "parts of time" that belong to (and express for us) its numerical structure. There are also "forms of time," namely the past and the future, which are connected to generation and corruption or, more generally, to the changes of material states of affairs. It is to the forms of time that Timaeus turns at some length, mostly in order to clarify our misuses of the linguistic idioms concerning time and tenses. This oft-commented upon clarification, which concerns less the issue of the planets than the metaphysical theory of time, I will leave for the "Postscript" to my contribution (see below; it is worth keeping in mind that Timaeus says more about how we speak about time than about time as such). Here I only wish to emphasize the basic distinction between the parts of time and the forms of time, a distinction which follows from the fact that only the forms of time, but not the parts of time, are connected to the flow of time or to "time's arrow" in the sense of things coming one after another in the unidirectional "before" and "after." In contrast, there will once again be a day after a night, and after this November there will once again be November next year. This, in and of itself, does not imply the irreducible difference of the content of what happens this November and the next November: it is me, not November that will grow older. November is, per $s e$, entirely indifferent to what was, is, and will be. That it is so is imperative in order for us to have time as arithmos, not in the sense of counting, endlessly, months and years one after another, but in the sense of there being a structure which enables us to differentiate between the temporal units which are days and months and years.

This much being clear, the translation quoted above still contains a sentence which would seem to threaten my suggestion that the proper image of eternity or eternal life (aiōn) is not time in the abstract, but planets as ensouled celestial bodies whose motions express time and make it intelligible for us. The sentence in question is rather tangled and follows from a general summarizing claim that the characteristics or features caused in the sensible things by generation do not belong to what is always changeless and motionless. To which Timaeus adds that

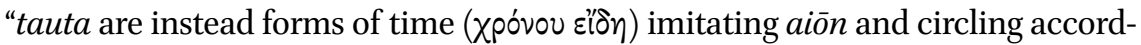
ing to number." It is obvious that tauta are the characteristics of generated and 
perishable things, which have a past and a future different from their present state. The quoted sentence is therefore a general statement, which is not a direct part of the narrative sequence of events: at this point of the story, no such generated and changing (yet particular) things are in existence.

Moreover, the sentence fits badly its present context as well since the evoked activity of imitating the eternal life should belong, at best, to the parts of time (time as structure), not to its forms (time as time's arrow). ${ }^{10}$ We should stress "activity" here since activity is what the verb mimeisthai implies. This is its first occurrence in Timaeus' speech but, throughout the dialogue, this verb usually describes an activity of a living being, whether this activity is exercised in its mind or its body. ${ }^{11}$ That the forms of time (in contrast to the parts of time connected to the planets) could be active in this way appears quite implausible. In the same vein, the mention of a cyclical revolution suits much better the constantly revolving parts of time than the past, present and future tenses. All these things considered, it seems that the quoted sentence presents us with a rather relaxed inclusive statement and, as such, it prepares the almost immediately following (and even more general) summary at $38 \mathrm{~b} 6-\mathrm{c} 3$. Before continuing to this summary, Timaeus himself concludes his digression on the parts and the forms of time by admitting that he will not try to be entirely rigorous in applying his own temporal distinctions. At this point, the distinction between the two views on time ("parts of time" versus "before and after") seems to already have receded into the background. This does not, of course, mean that this important and logical distinction loses something of its philosophical value. Nothing in the dialogue contradicts the basic assumption that time is not reducible to "the forms of time" (or the "before and after") since these are logically contingent on motion and change (starting perhaps with the elemental motion on which they would not be apparent phenomenally; but this is only relevant for the question of whether there is a directional time at the level of the elemental transformations - this question eludes our present context and will only be mentioned in the "Postscript," note 19).

10 I therefore do not think that Timaeus alludes here to the as yet uncreated chain of generations of perishable animals. On such a chain see, in contrast, Symposium 207d; it is reforged in Aristotle, De anima II 4, 415a26-b7.

11 Timaeus uses mimeisthai three times about the lesser gods imitating the Demiurge while creating mortal bodies, and then about our intellectual imitation of the regular celestial motions (46c7-47c4). At 81b1-2 it is used to describe how the blood particles in our

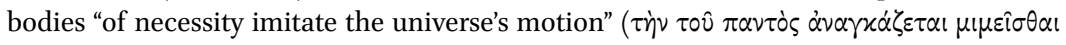

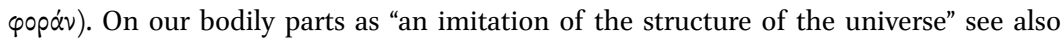
$88 \mathrm{c} 7-\mathrm{d}$. This "imitation" follows of course from divine intention that governs the making of our bodies. 
The already mentioned more general summary following on it confirms the independent role of "the parts of time" by first sketching an analogy between the eternal life of the model and the life of the universe, and then by finally passing - almost in the same breath - to the fabrication of planets as a means of making this analogy not only notional, but real:

Time, then, came to be together with the universe ( $\mu \varepsilon \tau^{\prime}$ ov่pavov̂) so that just as they were begotten together $(\ddot{\alpha} \mu \alpha)$, they might also be undone together $(\ddot{\alpha} \mu \alpha)$, should there ever be an undoing of them. And it came to

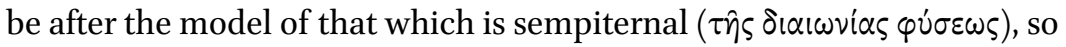
that it might be as much like its model as possible. For the model is some-

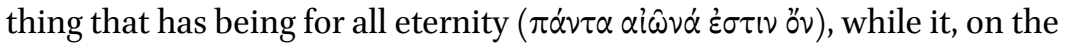

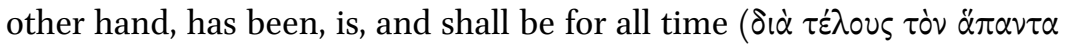

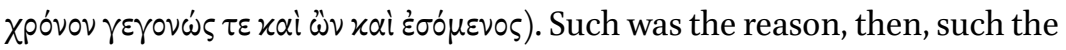

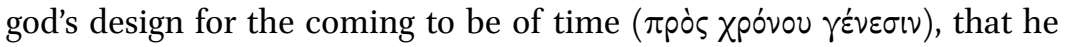
brought into being the Sun, the Moon and five other stars, for the begetting of time. These are called "wanderers," and they came to be in order

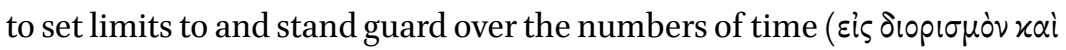
$\varphi v \lambda \alpha x \dot{\eta} v \dot{\alpha} \rho(\theta \mu \omega \hat{\omega} v$ xpóvov).

$38 \mathrm{~b} 6-\mathrm{c} 6$

We certainly do not need seven planets in order to make time pass from the future to the past; by contrast, we need them in order to express time as number in an organized and, in all its complexity, beautiful way. By the same token, time as number does not explain what we call the flow of time (even the world soul, once produced, simply starts to live its unceasing and intelligent life

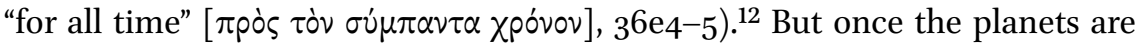
there, the universe becomes analogical to its model in virtue of being a well-

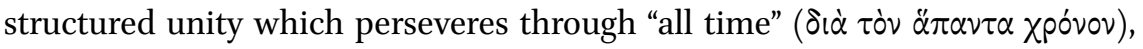
past, present and future alike. ${ }^{13}$

Here we should take a step back, just like the Demiurge did a moment ago, and take a panoramic look at where we are. First, it should be said that, until the invention of planets, the universe - or what will soon become a complex worldis not really measured by the degree of direct resemblance to its eternal model.

12 Cf. Goldin, "A Plato and the Arrow of Time," 133-134. And see the "Postscript" below.

13 A full-blown version of the resulting analogy appears in Calcidius' commentary, ch. cv: the mundus sensibilis relates to the parts of time in the same way as the mundus intelligibilis relates to eternity. See Bakhouche, ed., Calcidius: Commentaire au Timée de Platon, 338, and Magee, ed., Calcidius, On Plato's Timaeus, 297. 
This is because the model does not contain the blueprint of the world's body (although it arguably contains the geometrical blueprints of the elements), and it does not seem to encompass a soul which would be a blueprint for the world soul. The latter, much like the structure of the world's body, is produced by the Demiurge in his effort to make the world as good as possible. In this respect, we must not forget that the primary motivation of the good Demiurge is to make the world like himself (see 29e-3oa). Hence the choice of the perfect model, but also a certain double bind since "to make the world in my image" and "to make the world resemble an unchanging intelligible model" is not entirely the same thing. Those ancient interpreters who solved this tension by transplanting the model right into the mind of the Demiurge therefore proceeded logically, but they made a huge step beyond the letter of the dialogue which leaves the model metaphysically quite indeterminate except for a few general and mostly negative characteristics (absence of generation, absence of all change). It lacks all determinate properties that could directly guide an effort at its imitation. The expression noêta zöia (31a5), which describes what the model contains, is not a solution to this difficulty since it is hopelessly ambivalent: it can describe an entirely unknown and metaphysically original form of life, but it can just as well be the label for an intelligible Form of what the known life forms are like (this is the ambivalence between "the model is a living being" and "the model is of living beings").

In this situation, the decision to create the planets is both contingent upon the already established structure of the world soul (it makes use of the divisions within the circle of the Different) and largely independent of Timaeus' introductory and quite general description of the likeness between a generated entity and its eternal model. Even the world soul's structure is independent in the same sense: although it acquires a life of its own, it is first and foremost a means to guarantee the stability of the resulting overall likeness. The Demiurge will continue to be creative and resourceful concerning various ways of establishing the complex likeness in question: for instance, to take the most obvious case, the idea of producing the likenesses of the last two intelligible living beings by letting humans degenerate into them is not exactly how we usually imagine the relation between things and Platonic forms.

Having summarized the genetic coordination of heavens and time, Timaeus proceeds to describe the more technical aspects of how the planets came into being and of how they move according to their assigned numbers. This part of his discourse about planets was one already most discussed by the Ancients who-just like present-day commentators - try to make sense of the more technical or astronomical aspects of what Timaeus ventures about the "dancing motions" of the planets and "their juxtapositions and back-circling" (4Oc). 
I have nothing original to say on this count, ${ }^{14}$ and I am also not able to determine how exactly the planetary trajectories relate to the rotation of the corresponding circles of the world soul. ${ }^{15}$ So I will instead point out two simpler things.

First, planets are living creatures composed of a body and a soul, and it is apparently in virtue of their soul's activity that they do not deviate from their pre-determined orbits. This follows from their guardian role, specified as "cooperation in producing time" for which their bodies were "bound by bonds of soul": it is the latter that had "learned ( $\left.\varepsilon^{\prime \prime} \mu \alpha \theta \varepsilon v\right)$ their assigned tasks" (38e5-6). Hence the notion of planets as "instruments of time" (42d5) or "instruments of times" (41e5). This equivocation follows from the fact that each planet's motion must have its own numerical pattern whose expression is "what we call time."16 Timaeus confirms this clearly at 39d1-2: "time really is the wanderings of these

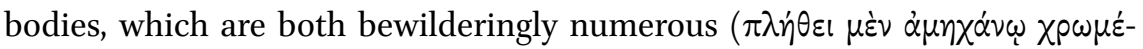
$\nu \alpha \varsigma)$ and astonishingly variegated ( $\pi \varepsilon \pi \circ(x \iota \lambda \mu \varepsilon \dot{v} \alpha \varsigma \delta \dot{\varepsilon} \theta \alpha \nu \mu \alpha \sigma \tau \hat{\omega} \varsigma)$." This rather unusual praise of visible complexity and variety anticipates upon Timaeus' final summary of why the planets are good for the universe: the purpose of their making "was to make this living thing [sc. this universe] as like as possible to that perfect and intelligible Living Thing, by way of imitating its eternal nature" (39d8-e2).

In other words, the planets, precisely in virtue of increasing the organized complexity of the universe, make the latter more like its model which consists of the intelligible living things. What the Demiurge achieves by construing the planets is the indirect imitation of the life present in the model's noetic composition: the model contains exactly four intelligible species of living being; the planets have no such noetic blueprints but are the newly conceived lifeforms whose motions exhibit regular complexity. This is strikingly different from what immediately follows in Timaeus' story, which is the creation of the fixed stars as the first step in completing the likeness of this universe to its model by a direct imitation of the exactly four species contained in the model.

14 On this issue, I tend to concur with Bowen, "Simplicius and the Early History of Greek Planetary Theory," 158, on Timaeus $38 \mathrm{c} 7-\mathrm{d} 6$ and the image of planets as runners: "All the image requires is a sense of the overall eastward direction of the race, and this itself may have been inferred from the fact that the planets rise later and later in relation to the fixed stars over the course of time. In any case, the image is no warrant for talk of planetary stations and retrogradations."

15 Nor, as far as I can tell, is anybody else; were they exactly the same, there would be no need for the planets to possess their own calculating souls: to firmly fix their bodies would be enough. On this usually overlooked problem see Mason, "The Nous Doctrine in Plato's Thought," 216-217.

16 See Brague, "Pour en finir," 62-63. For Proclus, this plurality is unified in the higher, intellectual time. 
Of these four species, which are implicitly attuned to the four elements, fixed stars, composed mainly of fire, are the first. Their creation thus marks a new stage in the whole story: until now, the Demiurge was creating the setting for the four species that will correspond to the equally four intelligible living beings. At the same time, this setting is not a neutral container and its function is not only to be beautiful and ordered in its motions. This order has its own value and its complex unity already does imitate, albeit indirectly, the intelligible character of the model, although it does not yet directly imitate the four intelligible living beings. ${ }^{17}$ Importantly-and this is the second thing I wish to point out - planets will play a role even in the completion of this new and direct imitation.

In this respect, the planets play a pivotal role in Timaeus' story in that they prepare the shift from the immortal visible species (fixed stars) to the mortal ones. The construction of the planets starts to make further sense once human beings are created as observers of cosmic complexity. At that moment, planets acquire a second, and then a third function which relate to human practical well-being and human intellectual progress respectively.

Concerning human well-being, Timaeus leaves no doubt that, on his account, there is a teleological connection between planets and the good things in human life. In order to better measure the slowness and quickness of all celestial motions, the Demiurge lights up the sun which helps all those who can be taught to "participate in number" $\left(39 \mathrm{~b}_{5}-\mathrm{c} 1\right)$. At $47 \mathrm{a}-\mathrm{b}$, it is confirmed that both planets and fixed stars are, together with the gift of sight, mankind's helpers in acquiring "the art of number" and "the notion of time." Apparently, this is not why the celestial bodies were created in the first place; but it is how the Demiurge deliberately uses them beyond their first purpose. And he will make further, more cunning use of the celestial bodies in orchestrating the conditions for the coming to be of the lower animal species, more exactly of those generated species that will be described as "lower" compared to other created species even if all created species are equal as likenesses of their respective intelligible models, and are therefore equally necessary for the universe to be complete (see $41 \mathrm{~b}-\mathrm{c}$ ).

It is at this point of the story that planetary motions will themselves become a model or a paradigm. This role will be part of their quite complicated - and not entirely clarified-relation to the immortal part of human soul fashioned by the Demiurge. The latter is said to have produced human intellects in the

17 For a succinct summary of this level of imitation (where complex construction takes place of simplicity) see Sattler, "A time for learning and for counting-Egyptians, Greeks and empirical processes in Plato's Timaeus," 253. 
same number as he had just produced the fixed stars, and then placed one intellect on each star in order to parade them all around the universe-and showing them the complex dance of the planets-while revealing to them the laws of their incarnation and announcing to them that "he would sow each

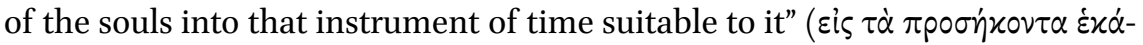

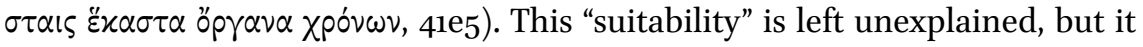
should imply that there are human beings on all the planets, and that the intellects, once detached from bodies, return from these planets to those fixed stars where they were placed before their first reincarnation on the planets. All in all, there is a lot of soul-travelling in between the circles of the Same and the Different.

These travels, however, belong to the souls' preordained place in the universe and this place is entirely different from the souls' epistemic relation to the planets and the fixed stars: the incarnate intellects should construe such a relation, by their own effort, in the guise of a homology between their own original structure and, apparently, the global structure of celestial motions. This last point follows from Timaeus' statement that to subdue irrational mass of our bodies means to handle ourselves in "conformity with the revolution of the Same and uniform" within us (42d1-2), a statement to be read together with the often quoted claim that more or less closes the first part of Timaeus' speech:

the god invented sight and gave it to us so that we might observe the

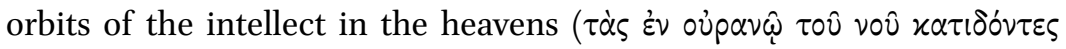
$\pi \varepsilon p$ ó $\delta 0 u \varsigma)$ while applying them $(\chi p \eta \sigma \alpha i \mu \varepsilon \theta \alpha)$ to the revolutions of our

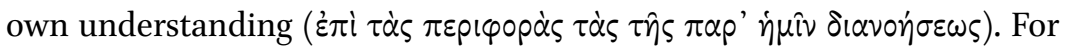
there is a kinship between them, even though our revolutions are disturbed, whereas the universal orbits are undisturbed. So once we have come to know them and to share in the ability to make correct calculations according to nature, we should stabilize the straying revolutions in ourselves ( $\tau \dot{\alpha} \varsigma \dot{\varepsilon} \nu \dot{\eta} \mu \hat{\imath} \nu \pi \varepsilon \pi \lambda \alpha \nu \eta \mu \dot{v} \nu \alpha \varsigma$ $\alpha \alpha \tau \alpha \sigma \tau \eta \sigma \alpha i \mu \varepsilon \theta \alpha)$ by imitating the

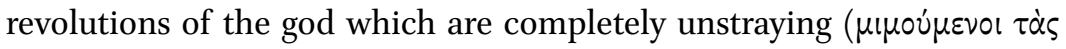

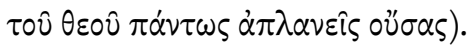

$47 \mathrm{~b} 6-\mathrm{c} 4$

This, just like the preceding lines about, again, days and nights and the art of number, is less about the revolution of the Same than about the complex orbits of the planets (Timaeus speaks about "orbits" in the plural). Still, since the "god" mentioned at $47 \mathrm{c} 4$ is clearly the universe, Timaeus brings all celestial bodies together again, regardless of their different origin. Here, as elsewhere, 
Timaeus sticks to his premise of a complete structural homology of the world soul on the one hand and the human intellect on the other hand (cf. $44 \mathrm{~d}_{3}-5$ on

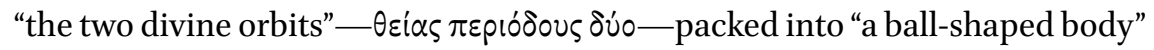
which is our head; see also 9oc6-d5).

Now the question is what to make, philosophically, of this homology, wherein the planets play a role which is epistemologically more complex than the role of the fixed stars in the circle of the Same. Apparently, it is the planets that give humans the initial nudge to search for the regularity beyond the constantly changing phenomenal variety for which the fixed stars offer a slow-moving background canvas - and the richness of this variety presents us with puzzles left unsolved by both Timaeus and the ancient commentators on his speech. This only underscores the difference between the two kinds of celestial beings and their relation to human beings. The fixed stars truly are like us in being the created likeness of the intelligible living model: they are like us from the perspective of similarly created artefacts. The planets, in contrast, only seem to be like us in virtue of their apparent disorder which, however, should remind us of something which is different from-and better than-our own disorganized state caused by the shock of our seemingly contingent birth.

To sum up, Timaeus describes the planets from two strikingly different angles: first as a brilliant invention of a true creator, but thereafter as a key element in the providential arrangement of the visible universe in view of the good terrestrial life. It is easy to find this second perspective congenial to Aristotelian teleology (at least as seen by commentators such as Alexander; cf. Simplicius In Aristotelis de cael. 421.7-33). But it is equally important to acknowledge the first perspective as a rare instance where Plato positively evaluates the phenomenal variety or poikilia and praises invention as such. In other dialogues, the latter is usually reserved for politics as a realm of second best options (the Republic, the Laws, and certainly the Statesman could all furnish us with examples). At the same time, something similar happens here too: the Demiurge deliberates while coping with various constraints and, in this respect, the Timaeus exhibits obvious connections to practical philosophy. This is why I gladly subscribe to the conclusions of Myles Burnyeat's article on eikōs mythos. ${ }^{18}$ But I also believe that the resulting universe is perhaps more of a patchwork than Burnyeat's reading implies and that it is difficult to see Timaeus' speech as a mirror of the discourse that establishes the best city in the Republic. This is because the latter may actually have less to do with practical philosophy while the Timaeus may retain a stronger connection to natural science than Burnyeat suggests. Timaeus' speech needs to account for what is 
experientially there, including planets that seem hard to tackle without bringing in some reference to a human presence in the universe. About the planets, Timaeus would then speak "plausibly" in much the same sense as Aristotle does in De caelo II 12, when he imagines their different orbits analogically to human activities. Both accounts are plausible in giving sense to a puzzling diversity, yet neither has the means to undo the puzzle by referring to an independent observational verification.

\section{1 \\ Postscript: Timaeus' Speech and Time}

Timaeus unhesitatingly evokes the flow of time even before the celestial time is there (or, in any case, as independent on the celestial time): see $36 e_{4}-5$ on the life of the world soul as continuing, unceasingly, "for all time" ( $\pi$ pòs tòv $\sigma \dot{\mu} \mu \pi \alpha v \tau \alpha$ Xpóvov). Here I wish to offer a few remarks on the implication of this "all time" as expressing the flow of time; I will raise this issue concerning both the world soul together with the created universe, and the latter's unchanging, everlasting model.

Timaeus' "all time" seems to be essentially tenseless even if:

(1) It allows for the distinction between "before" and "after" (see 37a-c on the world soul as pronouncing what it experiences in a clearly sequential manner: this soul's states cannot be simply interchangeable in respect of the direction of time, if only because Timaeus describes them in propositional terms, i.e. as a veridical internal speech about the composite states of affairs).

(2) It is time's flow - rather than "time as number" - that gets divided into the past, the present, and the future, with corresponding verbal tenses.

The expression pros ton sympanta chronon is therefore synonymous with dia ton hapanta chronon which is predicated, at $38 \mathrm{c} 2$, of the universe, together with the explanation that the latter "has been, is, and shall be for all time" ( $\delta \dot{\alpha}$

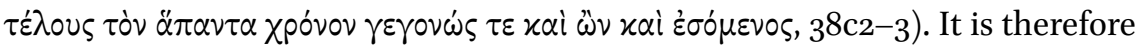
legitimate to speak about the duration of the universe in time, whether it is predicated of the world soul or of the universe as such. Note that this does not answer the question of whether there is time in the sense of either duration or the flow of time in respect of what "is always changeless and motionless." Regarding the latter, Timaeus says that it "cannot become either older or

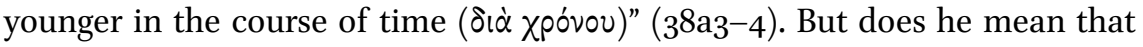
time may flow among eternal things but without them ageing (as they have no date of birth), or does he mean that, among eternal things, time does not flow at all? This ambiguity is left unexplained. 
By contrast, Timaeus clearly explains, at $38 \mathrm{c} 3-6$, that time as the number expressed by the planets was created precisely as an instrument that enables us to date events. Time as number therefore serves to impose some structure upon the flow of "all time"; it is not, however, constitutive of the latter. Moreover, time as number cannot explain the language of the tenses analyzed by Timaeus, no matter how loosely, at 38a8-b5. Briefly put, time as number (imposed upon the flow of time) and the tensed language used about time are not mutually explanatory. One of the results is that we do not know where time's directionality, which we observe on bodies and their behavior, and also in our soul, comes from. In this respect, there would seem to be a lot more to say than Timaeus actually says about the relation between time, the directionality of time, and soul. ${ }^{19}$

The situation where time as number and the tensed language are not conceptually unified but simply express different perspectives assumed by Timaeus in his speech, is similar to the problem of how to translate the sequential idiom of "before" / "after" into the past, the present and the future tenses: this is the problem associated nowadays with McTaggart.

McTaggart's article "The Unreality of Time" (Mind n. s. 17, 1908, 457-74) deals with two ways of conceptualizing time (which he finds incompatible):

A-series: employs past, present, and future as implying the changing status of the states of affairs (so that the future states will become present and then past).

B-series: an ordered and unchangeable sequence of the states of affairs (what is "before" relatively to some "after" will always remain so and vice-versa).

Timaeus' way of speaking would confirm the impossibility of an exact translation between these two idioms; moreover, neither is an exact expression of "time as number" nor lets itself be translated into the latter's structure. ${ }^{20}$

This limitation concerns the time of the world and in the world. There is, however, yet another problem, related to the above-mentioned ambiguity concerning the time's flow outside the universe: the problem of the present as a

19 Indeed, Timaeus speaks about the flow of "all time" or about "all eternity" only there where some thinking soul is present. Perhaps Timaeus comes close to the assumption, pondered by Aristotle, that time requires soul. This, then, would take the mutual transformations of elements (and thus the receptacle) out of time-or, at least, out of any directional time. Whether it is truly so would depend on a detailed analysis of Timaean account of the genesis of the four elements. For a suggestive analysis of this sort (without a thematic focus on time) see Broadie, Nature and Divinity in Plato's Timaeus, 173-242.

This is indirectly supported by the fact that the later Neoplatonic discussions of time, which bring in the Parmenides, focus on the issue of temporal series including the (divisive) status of the present and proceed quite independently of the structure of planetary motions. 
tense, and also as the "eternal present." On Timaeus' account, there are things about which only "is" can be legitimately predicated and this tense should only be used about what (metaphysically) "is" in the eternal present.

Timaeus therefore uses "is" in a way which takes it away from the temporal A-series, but still without implying that "is" should only refer to a truly timeless present. This is because he describes the unchanging Forms outside the universe as "intelligible living beings." Speaking of these as a "paradigm which

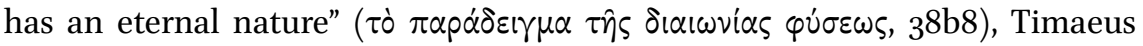
comes indeed close to indicating some ongoing process. The peculiar adjective diaiōnios ( $38 \mathrm{~b} 8$ and $39 \mathrm{e} 2$ ) can be understood as "through all aiōn": it designates the same kind of ongoing activity which is implied in the description of aiōn as staying/remaining (menontos) in unity (37d6).

There seems therefore to be an "eternal present" only in the sense of a specific temporality proper to something which actively sustains itself without any local motion or change.

Hence probably Iamblichus' idea that the unified and unmeasured aion is a measure (metron) for the noetic realm (In Tim. fr. 64): the latter, while motionless, cannot lack some sort of activity (aiōn as not timelessness but an ongoing uninterrupted activity; this connects to fr. 62 and the rejection of the Aristotelian connection between time and motion). ${ }^{21}$

In a similar vein, Proclus can claim that time in the sense of an unmeasured unity ("monadic" time) is better and more divine than soul (see In Tim. III 3.294.6; III 27.18-21), and is the same everywhere (III 57.15-27); Iamblichus and Proclus elaborate upon Timaeus' way of speaking about aiōn as itself diaiōnios or stretching in its own time.

This way of speaking might seem to resemble what McTaggart introduces as the C-series, of which he says that "it is not temporal, for it involves no change, but only an order," this order itself being not changeable (462). But the celestial time as number could correspond to this C-series even better: indeed, for McTaggart, only C-series in conjunction with change describable in terms of "before" and "after" generates the B-series in the sense of both regular and temporal pattern.

In Timaeus' speech, this conjunction is realized through the making of planets and the numerical prescription of their orbits. But, again, there is no "number" that could connect this cosmic clock to the eternal now. Moreover, on

21 Cf. Simplicius, Corollaries on Place and Time 789.16-18: "Is time the number of the earlier and later in motion rather than in rest? For likewise in the latter there is the earlier and later." See already Theophrastus' objection to Aristotle's account of the spheres: rest would seem to be a better way of imitating eternity than motion (Metaphysics $5^{\text {a23-28). }}$ 
both McTaggart's and Timaeus' account, this is still not enough to explain the unchanging direction of the temporal flow ("time's arrow"), which thus appears to be an independent constant.

To sum up: Timaeus offers no instructions for how to map various temporal idioms on each other; an independent ontology (the Neoplatonic one, the Hegelian one, etc.) will be needed to posit, more or less artificially, the transitions between various senses of "time." 22

\section{Works Cited}

Bakhouche, Béatrice, ed. Calcidius: Commentaire au Timée de Platon. Vol. I. Paris:Vrin, 2011.

Betegh, Gábor. "What Makes a Myth Eixw's?" In One Book, the Whole Universe: Plato's Timaeus Today. Edited by Richard D. Mohr and Barbara Sattler. Las Vegas: Parmenides Publishing, 213-226.

Bowen, Alan C. "Simplicius and the Early History of Greek Planetary Theory." Perspectives on Science 10 (2002): 155-167.

Brague, Rémi. "Pour en finir avec 'le temps, image mobile de léternité' (Platon, Timée, 37d)." In Du temps chez Platon et Aristote. Paris: PUF, 1982, 11-71.

Broadie, Sarah. Nature and Divinity in Plato's Timaeus. Cambridge: Cambridge University Press, 2012.

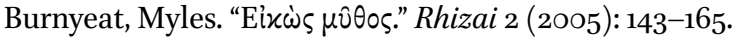

Cohen, Gerald L. "Etymology of Greek agalma, agallô, agallomai." Proceedings of the 2nd Annual Meeting of the Berkeley Linguistics Society (1976): 100-104.

Goldin, Owen. "Plato and the Arrow of Time." Ancient Philosophy 18 (1998): 125-143.

Johns, Jeff. "On the translation of Timaeus 38b6-c3." Études platoniciennes 11 (2014): §13 (accessible online at http://etudesplatoniciennes.revues.org/599).

Kerényi, Karl. "Agalma, eikon, eidolon." Archivio di Filosofia 1-2 (1962): 161-171.

Leftow, Brian. Time and Eternity. Ithaca: Cornell University Press, 1991.

Magee, John, ed. Calcidius, On Plato's Timaeus. Cambridge, MA: Harvard University Press, 2016.

Mason, Andrew S. "Why Does Plato Believe in a Timeless Eternity?" In New Essays on Plato: Language and Thought in Fourth-Century Greek Philosophy. Edited by Fritz-Gregor Herrmann. Swansea: The Classical Press of Wales, 2006, 177-188.

Mason, Andrew S. “The Nous Doctrine in Plato's Thought." Apeiron 46 (2014): 201-228.

22 The work was supported by the European Regional Development Fund-Project "Creativity and Adaptability as Conditions of the Success of Europe in an Interrelated World" (No. CZ.o2.1.01/0.o/0.o/16_019/oooo734). 
Sattler, Barbara. "A time for learning and for counting-Egyptians, Greeks and empirical processes in Plato's Timaeus." In One Book, the Whole Universe: Plato's Timaeus Today. Edited by Richard D. Mohr and Barbara M. Sattler. Las Vegas: Parmenides Publishing, 2010, 249-266.

Stump, Eleonore and Norman Kretzmann. "Eternity." The Journal of Philosophy 78 (1981): 429-458.

Thein, Karel. "Soul and Incorporeality in Plato." Eirene. Studia Graeca et Latina 54 (2018): 53-95.

Wilberding, James. "Eternity in Ancient Philosophy." In Eternity. Edited by Yitzhak Y. Melamed. Oxford: Oxford University Press, 2016.

Zeyl, Donald J. Plato: Timaeus. Indianapolis: Hackett, 2000. 